\title{
FATORES INFLUENCIADORES DO PROCESSO DE INTERNACIONALIZAÇÃO: O CASO DE UM COMPLEXO INDUSTRIAL ALIMENTÍCIO BRASILEIRO
}

\section{FACTORS INFLUENCING THE INTERNATIONALIZATION PROCESS: THE CASE OF A BRAZILIAN COMPLEX INDUSTRIAL FOOD}

Diego Echevengua Borges

Doutorando em Administração da Universidade Federal de Minas Gerais

Belo Horizonte, MG, Brasil

E-mail: diego.e.borges@hotmail.com

Maríndia Brachak dos Santos

Doutoranda em Administração da Universidade de Santa Maria

Santa Maria, RS, Brasil

E-mail: marindiabrachak@gmail.com

Vanessa Almeida da Silva

Doutoranda em Administração da Universidade de Santa Maria

Santa Maria, RS, Brasil

E-mail: va.almeida@hotmail.com

Maria Carolina Serpa Fagundes de Oliveira

Mestranda em Administração da Universidade de Santa Maria

Santa Maria, RS, Brasil

E-mail: mc.sfagundes@gmail.com

Flavia Luciane Scherer

Professora Adjunta da Universidade de Santa Maria

Santa Maria, RS, Brasil

E-mail: flaviascherer@globo.com

Maíra Nunes Piveta *

Mestranda em Administração da Universidade de Santa Maria

Santa Maria, RS, Brasil

E-mail: mairanpiveta@gmail.com

\section{RESUMO}

A fim de expandir os negócios, muitas empresas tomam a destemida decisão de abrir mercado e internacionalizar as suas operações. Desta forma, o objetivo deste estudo consiste em analisar os fatores que potencializaram a decisão da empresa Germani Alimentos em atuar no mercado internacional. Ademais, o estudo dedica-se na descrição das especificidades macroambientais e institucionais que podem exercer influência na decisão de internacionalizar. Para tanto, foi realizada uma pesquisa descritiva com abordagem qualitativa, por meio de um estudo de caso. Os dados foram coletados por intermédio de entrevistas aplicadas junto aos gestores empresa, bem como a análise de dados secundários. Os resultados mostram que os incentivos governamentais para a exportação influenciaram a empresa a buscar a internacionalização como alternativa de desenvolvimento.

Palavras-chave: Internacionalização. Fatores Influenciadores. Performance. Nível de Aspiração. Indústria Alimentícia.

\section{ABSTRACT}

In order to expand business many companies take the bold decision to open market and internationalize its operations. In this way, the aim of this study is to analyze the factors that have strengthened the company's decision Germani foods in acting on the international market. Furthermore, the study is dedicated to the description of the specific macroenvironmental and institutional particularities that may exert influence on the decision to internationalize. To this end, a descriptive research with qualitative approach, through a case study. The data were collected through interviews with company managers applied, as well as the analysis of secondary data. The results show that the Government incentives for the company to seek export influenced the internationalization as an alternative.

Keywords: Internationalization. Factors Influencing. Performance. Level of Aspiration. The Food Industry.

Data de aprovação: 16 de maio de 2016. 


\section{INTRODUÇÃO}

A partir de meados do século $X X$ e do desenvolvimento da economia brasileira, o governo vem oferecendo estímulos que auxiliam na melhor competitividade das empresas nacionais, tanto no mercado interno como no mercado externo (MENEZES, 2012). Podem-se citar, como exemplos destes incentivos, a oferta de financiamentos especiais pelo Banco Nacional do Desenvolvimento Econômico e Social (BNDES) e a criação da Agência Brasileira de Promoção de Exportações e Investimentos (APEX-Brasil). Tais estímulos fazem do ambiente institucional brasileiro, um cenário que possibilita às organizações a oportunidade de estarem em sintonia com o seu ambiente de negócio, a fim de prepararem-se para competir em diferentes mercados.

No que se refere à presença do Brasil no mercado internacional, o país é reconhecido como um competidor em ascensão, com uma forte posição no cenário global. No entanto, o Brasil ainda necessita de melhorias em sistemas como o de impostos, jurídico e burocrático. Os fatores infraestrutura, educação e incentivo à inovação mostram-se ainda incipientes exigindo investimentos regulares e relevantes com o propósito de consolidação da presença brasileira no mercado internacional (DELOITTE, 2012). Apesar disto, as empresas nacionais se encontram em fase de expansão no mercado estrangeiro e a crise nacional e desvalorização do real em relação ao dólar pode indicar a apreciação de novas fontes de oportunidades, em especial, ao comercializar no mercado internacional.

Dado o exposto, torna-se relevante analisar os fatores que podem exercer influência na decisão empresarial de internacionalizar-se, pois tal análise pode motivar a maior reflexão acerca das barreiras, das capacidades e vantagens deste processo no contexto brasileiro. E ao ter a citada circunstância como ponto de referência, o presente estudo adotou como objeto de estudo a empresa Germani Alimentos, uma das principais indústrias alimentícias do sul do Brasil, fundada em 1892 e de capital 100\% nacional. Em cinco anos no mercado internacional, via exportação, a Germani Alimentos expandiu sua área de atuação para países de diferentes continentes, participando de feiras internacionais para captação de novos clientes, desde o ano de 2009.

Em virtude disto, este artigo analisou os fatores competitivos que potencializaram a decisão da empresa Germani Alimentos em atuar no mercado internacional, ao tempo que verificou as variáveis que se relacionam com a decisão da empresa em expandir o âmbito de atuação para o exterior. Desta forma, o estudo descreve as especificidades macroambientais e institucionais que podem exercer influência na decisão de internacionalização.

No que se refere à estrutura geral de apresentação do presente trabalho, além desta introdução têmse o referencial teórico, abordando os fatores influenciadores da internacionalização, assim como também contextualiza a relação entre performance e nível de aspiração. Logo após, está delineada a metodologia utilizada na viabilização do estudo, os resultados, a conclusão do estudo e por fim, as referências. 


\section{REFERENCIAL TEÓRICO}

\section{Internacionalização: Fatores Influenciadores}

A internacionalização como um processo estratégico, pode ser entendida como o resultado de decisões organizacionais, as quais movem uma empresa por meio de diferentes e sucessivos estágios em seu processo de comercialização no mercado externo. Em cada fase, novos desafios estratégicos e prioridades decisórias serão encontrados (DOUGLAS; CRAIG, 1989) e, a partir desses acontecimentos, novos conhecimentos e habilidades podem ser gerados.

E em meio a esse cenário, diferentes fatores podem influenciar na decisão empresarial de comercialização no mercado externo, que pelo entendimento de Fabian, Molina e Labianca (2009) é elencado por forças do ambiente competitivo, variáveis do macroambiente e institucionais. Sendo complementado por Wennberg e Holmquist (2008) ao salientarem que a relação entre performance exportadora e nível de aspiração podem influenciar na decisão dos gestores em internacionalizar suas atividades.

A competitividade nos padrões internacionais possibilita às organizações a adaptação ao ambiente, a fim de adquirir a cooperação empresarial como forma de reduzir incertezas, compartilhar habilidades e informações. Ao enfatizar o mercado estrangeiro, a proposta de Fabian, Molina e Labianca (2009) apresenta fatores do ambiente competitivo como influenciadores do processo de internacionalização, tais como, os clientes, fornecedores, competidores nacionais e concorrentes estrangeiros, de acordo com o Quadro 01.

Quadro 01: Fatores do ambiente competitivo.

\begin{tabular}{|c|c|}
\hline $\begin{array}{c}\text { FATORES } \\
\text { COMPETITIVOS }\end{array}$ & DESCRIÇÃO \\
\hline Clientes & $\begin{array}{l}\text { Para atingir a competitividade no mercado internacional é necessário conhecer e satisfazer as } \\
\text { necessidades e expectativas dos clientes, valorizar o relacionamento com os mesmos e fidelizá- } \\
\text { los. Como exemplo, algumas empresas brasileiras do setor da construção civil buscaram o } \\
\text { mercado externo, a fim de sobreviverem no mercado competitivo, e perceberam que para ganhar } \\
\text { parcelas de mercado deve-se agregar valor aos clientes não só no mercado interno, mas resolver } \\
\text { seus problemas e satisfazer suas necessidades em todos os níveis (ALMEIDA; FARINA, 2007). }\end{array}$ \\
\hline Fornecedores & $\begin{array}{l}\text { A ida de um fornecedor chave para o mercado externo pode igualmente motivar um gerente a } \\
\text { tomar a decisão de internacionalizar, pois ao se engajar em tal processo a empresa evita os } \\
\text { elevados custos de transação de assumir novos fornecedores (PORTER, 1980). As transações } \\
\text { correntes no ambiente doméstico possibilitam que os fornecedores conheçam as capacidades de } \\
\text { seus clientes, e, em consequência disso, realizem com maior eficiência o cumprimento dos } \\
\text { acordos. Com isso, empresas fornecedoras tendem a seguir a expansão geográfica de seus } \\
\text { clientes devido a confiança conquistada ao longo das transações realizadas (ROMO; } \\
\text { SCHWARTZ, 1995; UZZI, } 1997 \text { apud FABIAN, MOLINA e LABIANCA, 2009). }\end{array}$ \\
\hline $\begin{array}{c}\text { Competidores } \\
\text { Nacionais }\end{array}$ & $\begin{array}{l}\text { A presença de fortes concorrentes nacionais em determinados setores pode levar algumas } \\
\text { empresas a diversificarem seus investimentos em outras nações com o intuito de reduzir os riscos } \\
\text { de atuar apenas no mercado nacional. Nesse contexto, Glória, Rocha e Levy (2013) colocam com } \\
\text { a entrada de fortes concorrentes nacionais e internacionais no varejo eletrônico, como as } \\
\text { empresas Ponto Frio, Casas Bahia e Walmart (as quais operavam apenas no varejo tradicional), } \\
\text { pressionou a companhia B2W, que controla as marcas Americanas, Submarino e Shoptime, a } \\
\text { internacionalizar suas operações para fugir da dependência do comércio eletrônico brasileiro. }\end{array}$ \\
\hline $\begin{array}{l}\text { Concorrentes } \\
\text { Estrangeiros }\end{array}$ & $\begin{array}{l}\text { Com a entrada de empresas multinacionais em mercados emergentes, firmas nacionais muitas } \\
\text { vezes são obrigadas a mudar suas estratégias, buscando expandir suas atividades para não } \\
\text { depender apenas das atividades do mercado nacional (MEYER, 2004). Stal e Campanário (2010) } \\
\text { ressaltam que com a intensa entrada de multinacionais a partir da década de 1990, as mais } \\
\text { dinâmicas empresas da América Latina se tornaram Multilatinas. Algumas, conforme os autores, } \\
\text { diante da pressão de concorrentes externos em seus territórios, se instalaram em outras regiões } \\
\text { do continente, como o Mercosul e na zona andina, bem como em mercados emergentes, como } \\
\text { África e Ásia. }\end{array}$ \\
\hline
\end{tabular}

Fonte: Adaptado de Fabian, Molina e Labianca (2009). 
Um padrão adequado de competitividade não é garantido apenas pela eficiência operacional, uma vez que, é necessário estabelecer uma posição privilegiada sustentada no ambiente, ou seja, o desempenho de uma organização é determinado por seu ambiente externo e pelas variáveis que compõem a estrutura da indústria (PORTER, 1999). Diante disto, os fatores sugeridos pelos autores Fabian, Molina e Labianca (2009) necessitam de monitoramento constante, a fim de não comprometer o desempenho da organização.

Com relação à internacionalização, devido às condições macroambientais do país, de acordo com Oliva et al. (2006), as empresas estão inseridas num ambiente influenciado por forças econômicas, socioculturais, político-legais, tecnológicas e físicas. Tais forças são constituídas de diversas variáveis que podem influenciar no desenvolvimento das estratégias corporativas. Logo, determinada empresa pode considerar, ao iniciar seu processo de internacionalização, alguns fatores intrínsecos ao ambiente nacional que elevam a demanda de seus produtos. Como por exemplo, o caso apresentado por Mangan et al. (2008) ao expor que face ao crescente número de imigrantes nos EUA, notadamente latinos, brasileiros, asiáticos e africanos, notou-se um aumento no interesse desses grupos em consumir produtos e serviços que são comuns em seus países de origem, oportunizando novos mercados aos negócios oriundos dessas regiões.

A riqueza de um país, a qual Machado e Pontili (2008) determinaram que pode ser medida pelo PIB (Produto Interno Bruto), pode atrair a entrada de empresas estrangeiras em seus mercados (QI, 2007). Logo, acredita-se que outros produtos brasileiros possam ser amplamente demandados no mercado, como por exemplo, pela falta de recursos naturais em alguns países ou porque determinadas nações se interessam por produtos da cultura brasileira, como é o caso da cachaça, bebida tipicamente brasileira bastante requisitada na Alemanha e nos Estados Unidos (CERIBELI et al., 2010).

No tocante aos fatores que pressionam à internacionalização de empresas, têm-se nações que possuem o ambiente doméstico hostil, no qual impera o desequilíbrio social, com seus problemas resultantes. Diante disto, essas questões podem induzir as empresas a buscarem o mercado internacional como alternativa para escapar das incertezas de atuarem em tais contextos (FABIAN; MOLINA; LABIANCA, 2009; SHIFTER; JAWAHAR, 2004).

Corroborando, empresas situadas em países em desenvolvimento, em algumas ocasiões, podem ser conduzidas ao mercado externo por mudanças dramáticas nas condições domésticas, tais como, altas taxas de inflação, desemprego e uma moeda instável, fatores que indicam situação econômica incerta (CATEORA, 1996). A saturação do mercado interno também pode instigar algumas empresas a iniciarem o processo de internacionalização, como apresentado por Tanure, Cyrino e Penido (2007) e Sandberg (2012) ao apontarem que as empresas se internacionalizam porque desejam manter suas taxas de crescimento quando o mercado doméstico já está saturado.

Empresas podem iniciar suas atividades no exterior a partir do mimetismo institucional, também denominado imitação, que se trata do caminho traçado no mercado internacional por organizações próximas de seu ambiente de atuação e que possuam características semelhantes as suas (tamanho, ano de fundação, região, por exemplo). A imitação pode ocorrer de forma consciente, com o intuito de se obter legitimidade no ambiente, ou inconscientemente devido ao fato do processo de internacionalização estar difuso e fazer parte da realidade de grande parte das organizações de um determinado território (ZUCKER, 1977; MEYER; ROWAN, 1977; WENNBERG; HOLMISQUIST, 2008). 
Wennberg e Holmquist (2008) pontuam que em certas circunstâncias, como em momentos de incerteza ou inexperiência, a internacionalização de uma empresa causa um alerta no mercado doméstico, conscientizando as empresas nacionais que o mercado internacional pode ser mais atrativo do que era pensado anteriormente. Fonseca e Machado da Silva (2002) colocam que existem razões suficientes, na literatura especializada, em especial no quadro de referências da teoria institucional, para compreender que a competitividade de uma organização não depende apenas de fatores econômicos e financeiros, mas sim, emerge também, a partir do estabelecimento de uma conduta socialmente aceita, que garanta sua legitimidade e sobrevivência no ambiente.

\section{Performance em comparação ao nível de aspiração}

As constantes mudanças no cenário mundial levam a refletir sobre as estratégias tomadas por empresas que se envolvem em negócios internacionais. Neste sentido, Wennberg e Holmquist (2008) ressaltam que a combinação da percepção dos problemas e ameaças no mercado interno, assim como a presença de oportunidades de negócios no mercado internacional podem ser um poderoso impulso para a internacionalização. No entanto, os autores defendem que os problemas internos são muitas vezes um forte desencadeador de esforços para a busca de ativos no mercado externo.

Madsen (2005) explica que a Teoria do Nível de Aspiração ou a Teoria de feedback da performance, baseia-se nos estudos de Simon (1955) e Cyert e March (1963) sobre a Teoria Comportamental da Firma (TCF). Nesta mesma linha de pensamento, Augier e March (2003) argumentam que o nível de aspiração comparado a performance está relacionado à ideia de que os tomadores de decisão interpretam os resultados como satisfatório ou insatisfatório, sendo, o nível de aspiração, o limite entre os dois. Níveis de aspiração são moldados por duas forças conjuntas: histórico de desempenho e comparação com empresas similares (CYERT; MARCH, 1963; LEVINTHAL; MARCH, 1981).

De acordo com Wennberg e Holmquist (2008), grande parte das pesquisas de comportamento sugere que se a performance for menor que o nível de aspiração, a empresa verificará que é necessário realizar melhorias em suas operações, e assim, passará a correr mais riscos na busca por novas experiências. Corroborando, Cyert e March (1963) ilustram que quando a performance for menor que o nível de aspiração, o entendimento em relação as necessidades de melhoria organizacional e quanto a novas formas de condução dos negócios irá aumentar, estimulando os empreendedores a realizarem pesquisas problemáticas, ou seja, voltando-se o foco para as oportunidades fora do mercado doméstico (WENNBERG; HOLMQUIST, 2008).

A internacionalização não se caracteriza como um processo distinto e separado das outras decisões estratégicas da empresa. Wennberg e Holmquist (2008) defendem que se por um lado uma estratégia de rápida internacionalização poderia facilmente ser suprimida ou adiada, dada as mudanças na performance, por outro, a internacionalização em alguns casos é considerada como uma alternativa de resgate quando há queda na performance, levando as empresas a dedicarem recursos escassos para os negócios internacionais.

Finalmente, quando a performance estiver acima do nível de aspiração, as empresas tendem a buscar novas oportunidades sem comprometer grandes quantidades de recursos. Em tempos de economia mais estabilizada, por exemplo, Wennberg e Holmquist (2008) colocam que as empresas buscam clientes por meio 
de descontos financeiros e costumam obter ideias por intermédio de seus colaboradores e/ou realizando experimentos.

\section{MÉTODO}

O presente estudo caracteriza-se, quanto aos fins, como uma pesquisa de natureza descritiva e abordagem qualitativa. No que se refere aos meios, faz-se uso do estudo de caso, pois busca descrever e analisar os fatores influenciadores no processo de internacionalização da empresa objeto deste estudo por meio de uma profunda investigação que objetivou obter o conhecimento amplo e detalhado a respeito do fenômeno em questão (GIL, 2002). A pesquisa apoia-se, ainda, no pensamento de Yin (2001), para o qual o estudo de caso refere-se a uma estratégia selecionada ao examinar acontecimentos contemporâneos, como é o caso da internacionalização de uma empresa do ramo alimentício.

No presente trabalho, foram desenvolvidas quatro categorias analíticas para auxiliar na resposta ao problema de pesquisa proposto, sendo estas: os fatores competitivos, fatores do macroambiente, o mimetismo institucional e a performance em comparação ao nível de aspiração. A operacionalização da pesquisa deu-se a partir de dados secundários, por meio de análise documental, com consultas em bibliografias e sites. Além disso, mediante a realização de análise do conteúdo, foram analisados os dados primários, advindos da aplicação de entrevistas semiestruturadas com três gestores responsáveis pelo setor estratégico, setor de produção e setor de exportação, tendo como base a análise das metas de vendas da empresa ao longo dos anos.

O modelo conceitual da pesquisa, apresentado na Figura 01, foi elaborado a partir dos modelos de Fabian, Molina e Labianca (2009) e de Wennberg e Holmquist (2008) que expressam quatro variáveis e suas possíveis relações com a decisão de internacionalizar atividades.

Figura 01- Fatores influenciadores na decisão da empresa em internacionalizar.

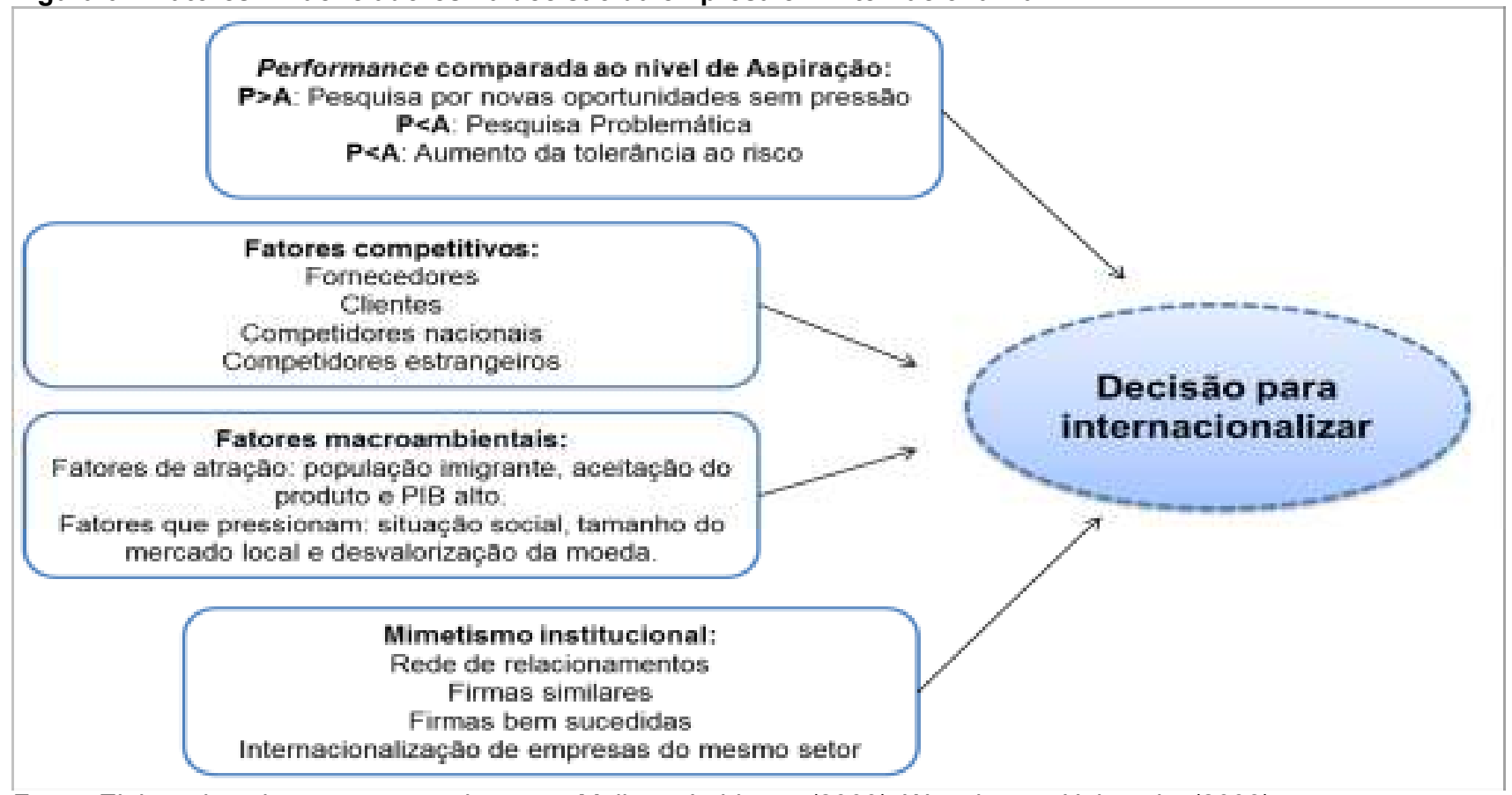

Fonte: Elaborado pelos autores com base em Molina e Labianca (2009); Wennberg e Holmquist (2008). 
As entrevistas ocorreram durante o mês de maio de 2013 e foram guiadas por um roteiro (protocolo) pré-estabelecido (YIN, 2001). O aporte de informações incluídas no protocolo foi obtido por meio de documentos, fotos, vídeos, histórias de vida, entrevistas, relatórios de pesquisa, arquivos de propriedade da empresa em estudo, etc.

A entrevista com os gestores foi transcrita e combinada, com outras fontes de dados presentes no protocolo de pesquisa. Após essa etapa, realizou-se a análise dos dados, utilizando a técnica de análise de conteúdo proposta por Bardin (1977). Nesta fase, foram quantificados e analisados a presença, os significados e os relacionamentos de palavras e conceitos nas entrevistas empreendidas, o que possibilitou a realização de inferências a partir das mensagens codificadas.

No Quadro 02 a seguir, encontram-se as variáveis, bem como os autores que embasaram o diagnóstico, conforme modelo apresentado, como sendo fatores influenciadores na decisão de internacionalização da empresa Germani Alimentos.

Quadro 02 - Fatores influenciadores na decisão de internacionalização da Germani Alimentos.

\begin{tabular}{|c|c|c|}
\hline $\begin{array}{c}\text { FATORES } \\
\text { INFLUENCIADORES }\end{array}$ & VARIÁVEIS & AUTORES PARA EMBASAMENTO \\
\hline $\begin{array}{c}\text { Performance } \\
\text { comparada ao nível de } \\
\text { Aspiração } \\
\end{array}$ & $\begin{array}{l}\text { Performance menor ou maior } \\
\text { que aspiração }\end{array}$ & $\begin{array}{l}\text { WENNBERG; HOLMQUIST, 2008; CYERT; MARCH, } \\
1963 .\end{array}$ \\
\hline \multirow{4}{*}{ Fatores competitivos } & Fornecedores & MEYER, 2004; STAL; CAMPANÁRIO, 2010. \\
\hline & Clientes & MEYER, 2004; STAL; CAMPANÁRIO, 2010. \\
\hline & Competidores nacionais & MEYER, 2004; STAL; CAMPANÁRIO, 2010. \\
\hline & Competidores estrangeiros & MEYER, 2004; STAL; CAMPANÁRIO, 2010. \\
\hline \multirow{2}{*}{$\begin{array}{l}\text { Fatores } \\
\text { Macroambientais }\end{array}$} & $\begin{array}{l}\text { Variáveis que atraem a } \\
\text { internacionalização. }\end{array}$ & $\begin{array}{l}\text { MINISTÉRIO DA AGRICULTURA, 2012; MINISTÉRIO } \\
\text { DO DESENVOLVIMENTO, INDÚSTRIA e COMÉRIO, } \\
2009 .\end{array}$ \\
\hline & $\begin{array}{l}\text { Variáveis que pressionam } \\
\text { internacionalização. }\end{array}$ & SATO; ANGELO, 2007. \\
\hline \multirow{4}{*}{ Mimetismo institucional } & Rede de relacionamentos & $\begin{array}{l}\text { MEYER; ROWAN, 1977; HAUNSCHILD; MINER, } \\
1997 .\end{array}$ \\
\hline & Firmas similares & $\begin{array}{l}\text { MEYER; ROWAN, 1977; DIMAGGIO; POWELL, 1991; } \\
\text { HAUNSCHILD; MINER, } 1997 .\end{array}$ \\
\hline & Firmas bem sucedidas & HAUNSCHILD; MINER, 1997. \\
\hline & $\begin{array}{l}\text { Internacionalização de empresas } \\
\text { bem sucedidas do mesmo setor. }\end{array}$ & HAUNSCHILD; MINER, 1997. \\
\hline
\end{tabular}

Fonte: Elaborado pelos autores. 


\section{DISCUSSÃO E ANÁLISE DOS RESULTADOS}

\section{Apresentação da empresa Germani Alimentos}

A Germani Alimentos foi fundada em 1892, por imigrantes vindos da Europa que produziam artesanalmente farinha de trigo em um pequeno moinho na serra gaúcha. Atualmente, a empresa, de capital $100 \%$ nacional, pertence ao conglomerado Francisco Stedile - conhecido também por sua atuação na área metal mecânica e possui, aproximadamente, 515 colaboradores. O parque fabril da Germani Alimentos, o qual possui grande capacidade produtiva de massas e biscoitos, localiza-se em Santa Cruz do Sul, no Rio Grande do Sul.

No complexo industrial são produzidos um mix formado por massas, biscoitos e cereais para as marcas Germani, Coroa, Filler e Corsetti. A empresa conta também, com uma unidade moageira e uma unidade de silos, em Caxias do Sul, no mesmo Estado, onde são triturados e armazenados milhares de toneladas de grãos de trigo. A farinha proveniente desses grãos abastece a unidade fabril e também é comercializada para indústrias e varejos de todo o Brasil.

Presente em diversos estados do país, a estrutura comercial da empresa atende a grandes redes de supermercados, varejos de pequeno, médio e grande porte, distribuidores e atacadistas. Além disso, a empresa também exporta para diferentes países, especificamente Libéria (com menos frequência), Angola, Uruguai e Paraguai. A Germani conta com uma qualificada equipe de funcionários que garante aos produtos fabricados o alcance dos padrões de qualidade internacional, mantendo-se constantemente atualizada, moderna e competitiva.

Em relação ao mercado externo, a organização iniciou seu processo de internacionalização por meio da atividade de exportação, em 2009, estando há seis anos no mercado estrangeiro. Logo, a Germani Alimentos expandiu sua área de atuação da América Latina para a América Central e África e está abrindo mercados na Ásia e na Península Arábica. A forma de captação de novos clientes dá-se mediante a participação em feiras de negócios.

No ano de 2010, a partir da substituição da gestora de exportação, ocorreu uma reestruturação completa do departamento de exportação da empresa, quando foram atualizadas as embalagens para outros idiomas e agregaram-se mais produtos para serem comercializados no mercado externo. Em 2014, a empresa foi agraciada com o Prêmio Exportação Rio Grande do Sul (RS), concedido anualmente pelo Conselho do Prêmio Exportação do RS - composto por entidades representativas do segmento no Estado, na categoria Destaque Setorial em Alimentos, mostrando a legitimidade da organização no mercado.

\section{Performance em comparação ao nível de aspiração}

Com base nas informações obtidas mediante a realização de entrevistas, verificou-se que, no período que antecedeu o ano de 2010, as metas de vendas para o mercado interno, assim como as metas estabelecidas para o mercado externo não se apresentavam satisfatórias. Deste modo, os gestores da empresa Germani verificaram a necessidade de reestruturar o setor estratégico no mesmo ano citado.

Em relação ao mercado internacional identificou-se que a performance da organização estava abaixo do nível de aspiração, pois o volume de exportação era inferior ao planejado. Uruguai e Paraguai constavam 
como países que a empresa geralmente exportava, porém sem frequência e com volume e proporção pouco expressivos. Além disso, a maioria das embalagens dos produtos não estava adaptada para idiomas como inglês e espanhol, demonstrando ainda um fraco envolvimento com o mercado exterior.

Porém, no ano de 2010, houve a contratação de um novo gestor para o departamento de exportação que buscou realizar um diagnóstico dos problemas que afetavam a empresa, tais como, falta de adaptação das embalagens dos produtos e pouca atratividade dos mesmos para os mercados alvo. Tal constatação vai ao encontro do pensamento de Cyert e March (1963) que elucidam que quando a performance for menor que o nível de aspiração, surge o entendimento em relação às necessidades de melhoria organizacional, o que leva à realização de pesquisas problemáticas para alcançar o mercado externo.

Neste sentido, o novo gestor buscou estabelecer algumas estratégias, como por exemplo, a atualização de algumas embalagens para os idiomas de inglês, espanhol, francês e árabe, com o intuito de aumentar a participação da empresa no mercado externo e a fim de atingir países situados nos continentes Africano e Asiático. Com isso, notou-se que as ações da Germani estão em consonância com o estabelecido por Wennberg e Holmquist (2008), os quais expõem que se a performance for menor que o nível de aspiração, a empresa verificará que é necessário realizar melhorias em suas operações, e assim, passará a correr mais riscos na busca por novas experiências.

Diante das estratégias executadas, houve a expansão dos negócios da organização para o continente Africano. A Angola foi um dos países a negociar com a empresa Germani, devido ao fato da língua portuguesa ser o seu idioma oficial, demonstrando proximidade comercial. As negociações com o país, em alguns momentos, apresentaram dificuldades, pois o local passou por Guerra Civil e houve problemas na obtenção da moeda oficial, o dólar. Percebe-se que apesar do risco de atuar em algumas nações no comércio internacional, como o citado caso, a empresa Germani não se mostrou avessa aos riscos, pois acredita possuir uma linha de produtos competitiva e diversificada. Para tanto, os gestores buscaram novos contatos com importadores e ampliaram o volume de clientes, a fim de agregarem valor aos produtos e possibilitar que sejam demandados no mercado externo.

Atualmente, a Germani tem atingido suas metas e está em processo de expansão no mercado nacional e internacional. Os países em negociação, no ano de 2014, são: Arábia Saudita, lêmen, Índia, Paquistão, Haiti, Porto Rico, Estados Unidos, Argélia, Marrocos, Chile, Peru, Equador, Bolívia, Argentina e México, demonstrando a expansão para diferentes continentes. Conforme entrevistas realizadas, consta que a meta aumentou em $200 \%$ em relação aos objetivos organizacionais, devido aos excelentes resultados atingidos em 2013. Portanto, a empresa segue estipulando metas ambiciosas com o objetivo de ampliar ainda mais seu escopo de atuação.

Em relação à performance, com base nos estudos de Wennberg e Holmquist (2008) e Cyert e March (1963), verificou-se que embora a empresa apresente uma performance em crescimento, ainda não há indícios de que esteja acima da aspiração, já que a busca por novas oportunidades, ainda apresenta comprometimento de grande quantidade de recursos e tempo.

De maneira geral, percebe-se que a organização está em plena expansão para o mercado internacional e à medida que os objetivos da empresa em estudo estão sendo alcançados, esta tende a estabelecer metas maiores em virtude de suas ações estratégicas estarem sendo bem sucedidas no mercado 
externo. $\mathrm{O}$ quadro 03 apresenta trechos das entrevistas que apontam as evidências que foram discutidas nos resultados desta dimensão.

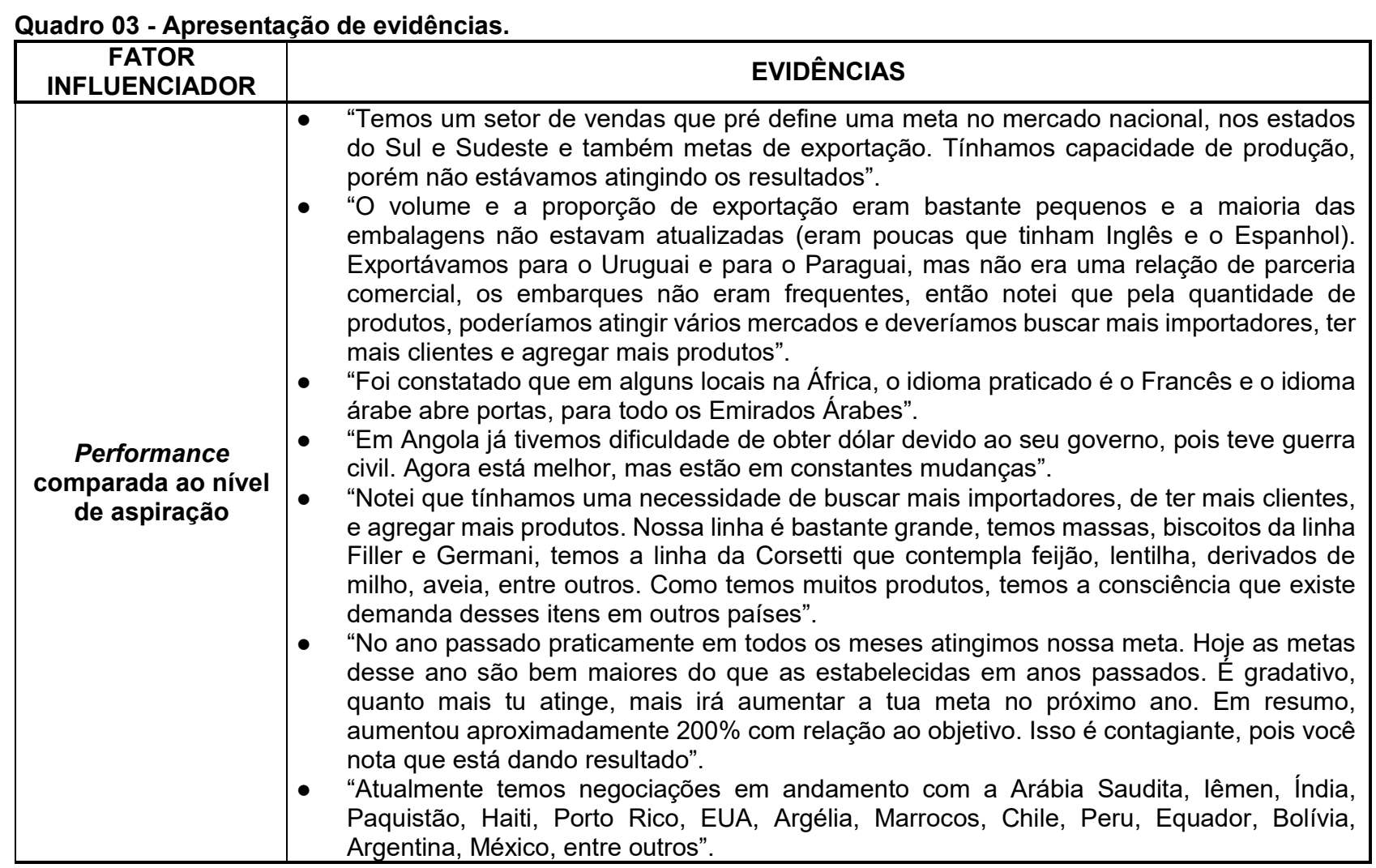

Fonte: Dados provenientes das entrevistas.

Fatores do ambiente competitivo

Ao indagar os gestores sobre a internacionalização de clientes e fornecedores, bem como de competidores nacionais, verificou-se que os mesmos não possuem relação com a decisão de a empresa internacionalizar suas atividades, não representando com isso, fatores competitivos para a organização em estudo. Uma possível explicação justifica-se pelo fato de clientes da empresa não estarem internacionalizando-se, já que o setor supermercadista brasileiro, a partir de 1995, recebeu inúmeras multinacionais estrangeiras pertencentes a grupos holandeses, franceses e americanos (SEGRE; WERNER, 2003; NASCIMENTO et al. 2007). E, portanto, houve um acréscimo de organizações multinacionais que adquiriram empresas nacionais de menor porte no país.

Além do exposto, o setor alimentício brasileiro vivenciou nos últimos anos uma onda de crescimento e encontra-se estabilizado. Em decorrência disto, acredita-se que a concorrência de marcas nacionais não ofereça riscos ao posicionamento da Germani Alimentos no mercado internacional, já que é necessário o desenvolvimento de estratégias diferenciadas para concorrer em diferentes mercados.

Dentre os fatores do ambiente competitivo, foi verificado que a entrada no mercado doméstico de concorrentes estrangeiros, por meio da comercialização de produtos como massas, principalmente de origem uruguaia e italiana, influenciou a saída da empresa para o exterior. Esse posicionamento vai ao encontro dos estudos de Meyer (2004) e Stal e Campanário (2010) que ressaltam que a entrada de empresas estrangeiras no mercado nacional influencia na decisão de empresas nacionais diversificarem riscos ao buscar o comércio 
internacional para não depender apenas da clientela de seus países de origem. A seguir, no Quadro 04, é apresentado o trecho da entrevista que aponta as evidências que foram discutidas nos resultados da dimensão.

Quadro 04 - Apresentação de evidências.

\begin{tabular}{|c|l|}
\hline $\begin{array}{c}\text { FATOR } \\
\text { INFLUENCIADOR }\end{array}$ & \multicolumn{1}{c|}{ EVIDÊNCIAS } \\
\hline $\begin{array}{c}\text { Fatores } \\
\text { competitivos }\end{array}$ & $\bullet \begin{array}{l}\text { "Existem fornecedores estrangeiros que fornecem principalmente massas. Inclusive, } \\
\text { muitas massas uruguaias e italianas são vendidas em Santa Cruz - eu diria no Brasil. } \\
\text { Notamos que os concorrentes do Uruguai confrontam com as nossas vendas, porque eles } \\
\text { têm um trigo diferenciado. É uma massa com mais nutrientes e impacta nas nossas vendas } \\
\text { no mercado nacional". }\end{array}$ \\
\hline
\end{tabular}

Fonte: Dados provenientes das entrevistas.

\section{Fatores do macroambiente}

Diante dos fatores macroambientais, foram levantadas as variáveis que atraem a internacionalização, bem como as variáveis que pressionam esse processo. Quanto às variáveis que atraem, constatou-se que a decisão estratégica de internacionalizar advém de proximidade geográfica e cultural, bem como das deficiências de um país em atender seu mercado interno, uma vez que, a empresa atua em países como Angola, Paraguai e Uruguai.

A Angola apresenta dificuldades em produzir produtos alimentícios que supram a demanda do país, o que atrai a entrada de empresas estrangeiras em seu mercado. Além disso, o uso do idioma português pela população angolana mostra-se um fator atrativo para a empresa Germani ter decidido investir nesse país, demandando poucos investimentos na adaptação dos produtos da marca. As considerações assemelham-se ao posicionamento de Sato e Ângelo (2007) que relacionam o grande volume de exportação de vinhos do Brasil para a Angola com o fato de o português ser a língua oficial do país, o que para os autores aproxima culturalmente ambos os países, facilitando, assim, o processo de exportação.

A proximidade física de países como Paraguai e Uruguai com as cidades brasileiras mais desenvolvidas em matéria de setor terciário tende a facilitar, sobremaneira, a exportação de serviços em todos os modos de prestação e também pode favorecer o fluxo de investimentos brasileiros em nichos de mercado insuficientemente providos por empresários locais, como distribuição e vendas no varejo e atacado (supermercados, lojas de departamento).

Cabe ressaltar, ainda, que a empresa possui uma linha de produtos consideravelmente grande, oferecendo massas e biscoitos, assim como feijão, lentilha, derivados de milho, aveia, entre outros. O que faz com que esses produtos possam ser amplamente demandados no mercado internacional, especialmente em mercados importadores desses alimentos, tais como, Argélia, lêmen e Angola que não possuem estrutura para abastecer de forma autossuficiente sua população.

Averiguou-se que o fato de existirem comunidades de brasileiros no exterior não representou influência na decisão da Germani de internacionalizar suas atividades, já que a maior demanda dos emigrantes brasileiros advém de produtos étnicos, como cachaça, churrasco e tortilla - no caso dos fabricantes mexicanos - os quais a empresa Germani não oferta (BORGES, REIS e FLEURY, 2009).

Como fatores que pressionaram a internacionalização, buscou-se levantar questões relacionadas à situação social, tamanho do mercado local e desvalorização da moeda (CATEORA, 1996; TANURE; CYRINO; 
PENIDO, 2007; SANDBERG, 2012), porém não foram averiguadas influências de qualquer uma das variáveis elencadas no processo de internacionalização da empresa objeto do estudo. Entretanto, o alto preço dos fretes de mercadorias e existência de muitas taxas e impostos no mercado nacional, assim como a isenção de impostos na exportação, são fatores que influenciaram a empresa em seu processo de internacionalização.

Com base nas entrevistas, ainda que o Brasil apresente desequilíbrios econômicos e sociais, a empresa Germani Alimentos segue mantendo suas atividades no mercado nacional, devido à expansão do consumo por produtos alimentícios no país. O Quadro 05 apresenta segmentos das entrevistas que compravam o que foi discutido nesta dimensão.

Quadro 05 - Apresentação de evidências.

\begin{tabular}{|c|c|}
\hline $\begin{array}{c}\text { FATOR } \\
\text { INFLUENCIADOR }\end{array}$ & EVIDÊNCIAS \\
\hline $\begin{array}{c}\text { Fatores } \\
\text { macroambientais }\end{array}$ & $\begin{array}{l}\text { - } \quad \text { "Em Angola, eles não possuem mão de obra qualificada, não tem maquinário, então eles } \\
\text { importam grande parte de alimentos, desde arroz, farinha, biscoitos. Em Angola eles falam } \\
\text { português, então facilitam as negociações e divulgação do produto. Notamos então que } \\
\text { em Angola seria um lugar propício para exportar. Possuímos contrato de exclusividade } \\
\text { com os importadores para não ter conflito entre as marcas e assim não oferecemos nossos } \\
\text { produtos a outros importadores de lá". } \\
\text { "Hoje a nossa dificuldade no mercado nacional é vender nos estados mais acima, devido } \\
\text { à questão logística, pois o frete se torna muito alto para regiões do norte e nordeste. É uma } \\
\text { dificuldade que nós estamos enfrentando. Quanto à exportação, quando nós vamos } \\
\text { oferecer um produto para um determinado país, é necessário verificar o frete daqui de } \\
\text { Santa Cruz até Rio Grande, além das despesas portuárias. Não tem ICMS, nem impostos } \\
\text { na exportação, o que é um facilitador e benéfico. No mercado nacional as taxas e impostos } \\
\text { são muito elevadas, além de despesas de frete, nas quais se tornam pontos negativos na } \\
\text { negociação". } \\
\text { "(...) Eu acredito que o consumo no Brasil vai permanecer, mesmo tendo muitas empresas } \\
\text { atuando no mercado (...)". }\end{array}$ \\
\hline
\end{tabular}

Fonte: Dados provenientes das entrevistas.

\section{Fatores miméticos institucionais}

Os fatores miméticos institucionais pesquisados com os gestores relacionaram-se à rede de relacionamentos, firmas similares, firmas bem-sucedidas e pressões normativas. Aspectos econômicos, tais como, incentivos à exportação influenciaram a organização para internacionalizar, porém a empresa não se detém apenas a estes aspectos. Identificou-se que as redes de relacionamento da empresa expandiram-se devido à participação em feiras de negócios, como a International Sweet and Biscuit Fair Cologne (ISM), em Colônia, na Alemanha, a Gulfood, em Dubai e também a China World Brands Import Fair (Chimport), na China. Neste sentido, a estratégia de participação em feiras auxiliou na captação de novos mercados, expandindo contatos e conquistando novos clientes, em virtude da apresentação do negócio para o mercado estrangeiro.

A entrada bem-sucedida de empresas do mesmo ramo de alimentação no mercado internacional também possui forte relação com a internacionalização da Germani Alimentos. O sucesso das principais concorrentes, que atuam no segmento de alimentos, influenciou a organização a vislumbrar oportunidades no mercado internacional, servindo de modelo para a estruturação do composto de marketing em consonância com as exigências de mercado de países desconhecidos.

Constatou-se ainda que, os incentivos governamentais, na forma de isenção de impostos para exportação, são instrumentos facilitadores e, por isso, influenciaram na decisão da empresa em atuar no mercado externo. Pesquisadores de teoria institucional consideram que estímulos oriundos do governo ou de 
associações do setor podem ser entendidos como pressões normativas que, caso não sejam respeitadas, podem originar sanções a empresas que a ignoram (MEYER e ROWAN, 1977; DIMAGGIO; POWELL, 1991).

Contudo, evidencia-se que aspectos econômicos foram levados em consideração pelos gestores da empresa devido aos estímulos governamentais para internacionalização. No Quadro 06 a seguir, um trecho que comprova as evidências encontradas nesta dimensão de análise é apresentado.

Quadro 06 - Apresentação de evidências.

\begin{tabular}{|c|c|}
\hline $\begin{array}{c}\text { FATOR } \\
\text { INFLUENCIADOR }\end{array}$ & \multicolumn{1}{c|}{ EVIDÊNCIAS } \\
\hline \multirow{2}{*}{ Fatores miméticos } & $\begin{array}{l}\text { "Algumas vezes buscamos informações, novidades dos concorrentes. Por exemplo, um } \\
\text { determinado concorrente no setor alimentício muito forte que atualmente está exportando } \\
\text { para muitos países, decidiu criar uma unidade produtiva nos EUA, de tanta demanda que } \\
\text { eles têm nos EUA. Sabemos que existe a demanda para o produto, tendo boa qualidade, } \\
\text { boa apresentação, embalagem atrativa, o que faz com que o cliente tenha vontade de } \\
\text { comprar o produto". }\end{array}$ \\
\hline
\end{tabular}

Fonte: Dados provenientes das entrevistas.

Por fim, com os resultados obtidos neste estudo, acredita-se que diversos fatores influenciaram na internacionalização da empresa Germani Alimentos. Como fator principal e decisivo têm-se a performance abaixo do que se esperava, no ano de 2010, tanto nos mercados interno e externo. Sendo assim, a contratação de um gestor capacitado para o setor de exportação supriu os objetivos organizacionais, mediante a elaboração de novas estratégias para o mercado internacional, o que garantiu a expansão da organização. Além disso, os incentivos governamentais para a exportação facilitaram o desenvolvimento da empresa a buscar patamares mais complexos. As constatações acerca desses influenciadores de internacionalização da Germani Alimentos são apresentadas por meio da Figura 02.

Figura 02- Fatores influenciadores na decisão de internacionalizar, da Germani Alimentos

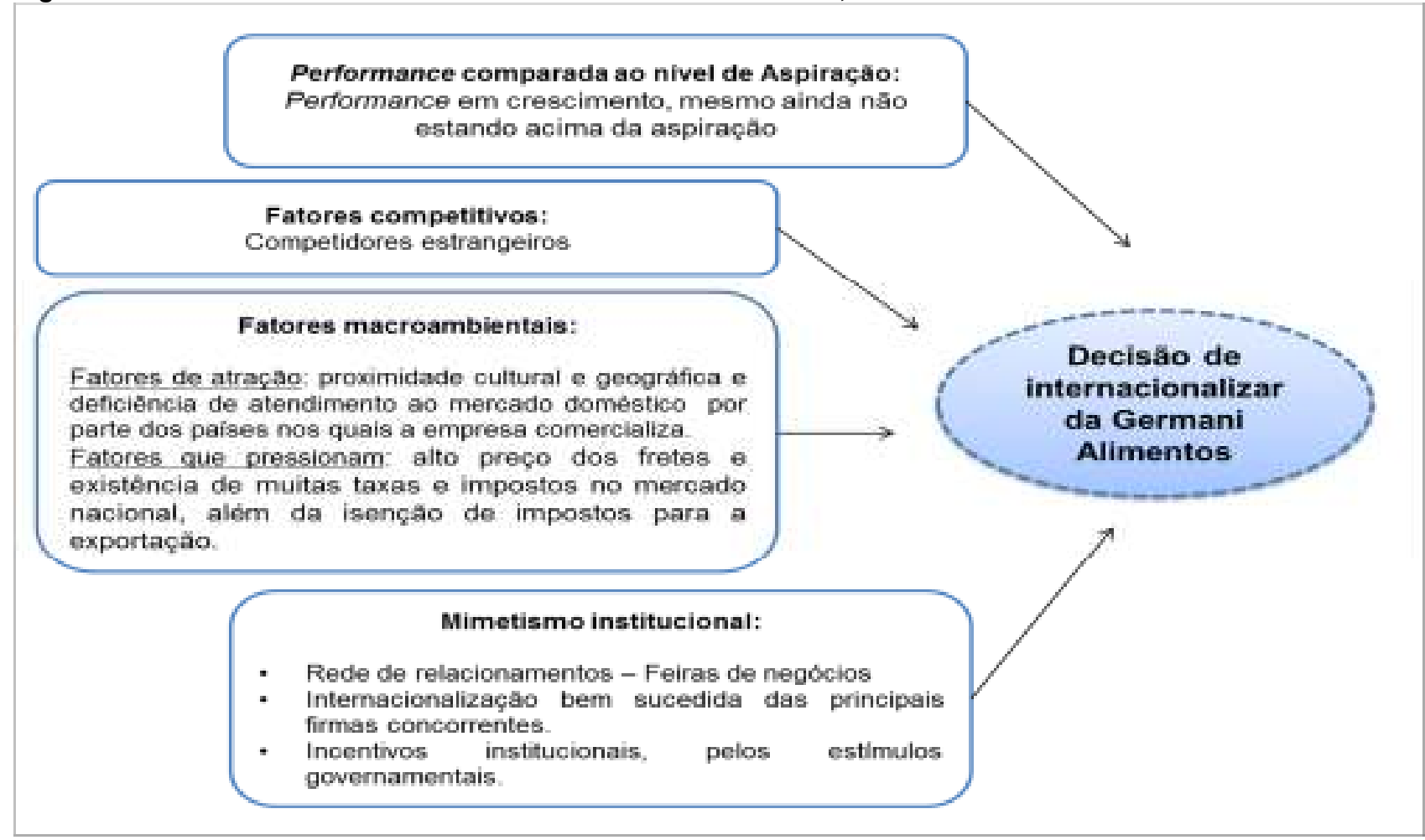

Fonte: Dados da pesquisa 
Com o exposto, infere-se que a avaliação de performance e estímulos institucionais, assim como determinados fatores competitivos e macroambientais desempenharam considerável influência na decisão estratégica da empresa estudada a voltar-se para o mercado internacional e dar início ao seu processo de internacionalização.

\section{CONSIDERAÇÕES FINAIS}

Tendo como referência os estudos de Fabian, Molina e Labianca (2009) e de Wennberg e Holmquist (2008) o presente trabalho objetivou analisar os fatores competitivos que potencializaram a decisão da empresa exportadora Germani Alimentos em atuar no mercado internacional. Além disso, buscou-se verificar as variáveis que se relacionam com a decisão da empresa em expandir a sua atuação comercial para o exterior, bem como verificar variáveis macroambientais e institucionais do processo de internacionalização. Com isso, constatou-se que algumas ações e certos atributos da empresa estudada, bem como fatores externos a mesma, influenciaram em sua decisão de adentrar no comércio internacional.

A performance abaixo do que a empresa almejava quanto aos objetivos traçados, resultou na reestruturação da organização, principalmente do setor de exportação, com a contratação de um novo gestor, no ano de 2010. Para tanto, foram estabelecidas ações de marketing para aumentar o volume de vendas, tanto no mercado interno, quanto externo. Ressalte-se, ainda, que o momento atual da empresa pode ser considerado satisfatório, pois a organização além de estar atingindo as metas de exportação e vendas internas, encontra-se em fase de negociações com importadores de vários países.

Os fatores que influenciaram na decisão de internacionalizar da Germani Alimentos não se limitam ao macroambiente, já que a linha de produtos, aliada à perspicácia dos gestores em adaptar o composto de marketing às especificidades do mercado internacional, representaram variáveis que exerceram forte influência na decisão de iniciar o processo de internacionalização.

O Brasil tornou-se, por um determinado período de tempo, um mercado atrativo para empresas. Em virtude disso, a organização em estudo buscou investir recursos tanto no mercado nacional, quanto internacional. Porém, a modificação de posicionamento da Germani Alimentos apresenta-se coerente, já que não atua de forma passiva no mercado, pois diante da velocidade da concorrência globalizada, depender de uma cartela limitada de clientes colocaria a empresa em um patamar elevado de risco.

Complementando, os fatores institucionais, como a carga de impostos e a incidência de excessivas taxas no transporte rodoviário brasileiro, afetam a competitividade dos preços da empresa em outros estados brasileiros, demonstrando barreiras para o crescimento no mercado doméstico. Este aspecto, aliado aos incentivos governamentais acabou influenciando a empresa a buscar o comércio internacional como alternativa de desenvolvimento.

As capacidades e vantagens do processo de internacionalização para empresas brasileiras podem ser apresentadas por meio do caso da empresa Germani Alimentos, que adaptou e investiu recursos para ampliar seus negócios no mercado externo, por meio da remodelação de seu composto de marketing, aumentando assim a sua competitividade. Com isso, a organização melhorou sua performance em relação aos objetivos traçados, bem como ganhou legitimidade no mercado interno, demonstrado pelo prêmio conquistado no ano de 2014. 
O estudo possui como fator limitante, o fato de tomar como objeto de investigação um único caso, que neste estudo, foi o da empresa Germani Alimentos em virtude de sua experiência no mercado nacional, porém o mesmo não pode refletir a realidade que prepondera na estrutura mercadológica brasileira. Cabe ressaltar que devido ao método de pesquisa empregado, os achados da investigação não podem ser generalizados.

Por fim, ainda assim acredita-se que as informações podem contribuir para o entendimento mais profundo dos fatores que levam as empresas brasileiras a buscarem o mercado internacional. Ainda, sugerese a ampliação da investigação para um maior número de empresas do setor alimentício, bem como de outros setores exportadores buscando contribuir para o campo dos negócios internacionais.

\section{REFERÊNCIAS}

ALMEIDA, A. D.; FARINA, M. C . Gestão do conhecimento em uma empresa internacionalizada com administração descentralizada: análise da capacidade de integração e manutenção das competências. Revista Eletrônica de Gestão Organizacional, v. 5, p. 39-51, 2007.

AUGIER, M.; MARCH, J. G. The economic psychology of Herbert A. Simon: introduction to a special issue. Journal of Economic Psychology, v. 24, n. 2, p. 135-141, 2003.

BARDIN, L. Análise de conteúdo. Lisboa: Edições 70, 1977.

BORGES, J. F.; REIS, G. G.; FLEURY, M. T. L. Da América Latina para o Mundo: a Internacionalização de Empresas Latino-Americanas que atendem ao Consumo Final de Alimentos. In: IV Encontro Estudos em Estratégias - 3Es, 2009, Recife. IV Encontro Estudos em Estratégias - 3 Es, 2009.

CATEORA, P. R. International Marketing. 9. Ed. Homewood: Irwin, 1996.

CERIBELI, D. L.; DA SILVA, D.F.; QUEIROZ,I.G.; FERREIRA,C.L.; CORONEL, D.A.; LÍRIO,V.S. Orientação regional e competitividade do agronegócio da cachaça para a Alemanha e os Estados Unidos.Revista de Política Agrícola. № 3 Jul./Ago./Set. 2010.

CYERT, R. M.; MARCH, J. G. A behavioral theory of the firm. Prentice-Hall, Englewood Cliffs, NJ, 1963.

DELOITE. Competitive Brazil: challenges and strategies for the manufacturing industry. Disponível em:<http://www.deloitte.com/assets/Dcom-brazil/Local\%20Assets/

Documents/Ind\%C3\%BAstrias/Manufatura/livro ingles.pdf>. Acesso em: 18 jul. 2013.

DIMAGGIO, P. J. POWELL, W. W. The iron cage revisited: institutional isomorphism and collective rationality in organizational fields. In: POWELL e DiMAGGIO. The new institutionalism in organizational analysis. pp. 63-82. Chicago: The University of Chicago Press, 1991.

DOUGLAS, S. P.; CRAIG, C. S. Evolution of Global Marketing Strategy: scale, scope, and synergy. Columbia Journal of World Business, p.47-59, Fall. 1989.

FABIAN, F.; MOLINA, H.; LABIANCA, G. Understanding Decisions to Internationalize by Small and Medium-sized Firms Located in an Emerging Market. Manag int Rev. 49: PP. 537-563, 2009.

FONSECA, V. S., MACHADO-DA-SILVA, C. L. Conversação entre abordagens da estratégia em organizações: escolha estratégica, cognição e instituição. Organizações \& Sociedade, v. 9, n. 25, p. 93-109, set./dez, 2002.

GIL, A. C. Como elaborar projetos de pesquisa. São paulo: Ed. Atlas. 175p. 2002.

GLÓRIA, T. B.; ROCHA, A.; LEVY, B. P. A Internacionalização da B2W Companhia Global de Varejo. Revista brasileira de casos de ensino. Vol. 3, No. 1. Jan./jun. 2013.

HAUNSCHILD, P. R.; MINER, A. S. Modes of Interorganizational Imitation: The Effects of Outcome Salience and Uncertainty, Administrative Science Quarterly, 42, 3, 1997, pp. 472-500. 
LEVINTHAL, D., J. G. MARCH. A model of adaptive organizational search. J. Econom. Behav. Organ. 2 307-333, 1981.

MACHADO, E. F.; PONTILI, R. M. PIB, Taxa Selic e sua influência sobre os investimentos em formação de capital fixo na economia brasileira. VII Seminário do centro de ciências sociais aplicadas. Campus de Cascavel. Cascavel - PR

-17 a 19 de junho de 2008.

MADSEN, T. K. Internationalization research: The impact of the Carnegie school. Scandinavian Journal of Management, v. 21, n. 4, p. 373-384, 2005.

MANGAN, F.; MENDONÇA, R. U.; MOREIRA, M.; NUNES, S. V.; FINGER, F. L.; BARROS, Z. J.; GALVÃO, H.; ALMEIDA, G. C.; SILVA, R.; ANDERSON, M. D. Production and marketing of vegetables for the ethnic markets in the United States. Hortic. Brasileiro. v.26, n.1, pp. 6-14. 2008.

MEYER, J. W.; ROWAN, B. Institutionalized Organizations: Formal Structure as Myth and Ceremony, American Journal of Sociology, 83, 2, pp. 340-363, 1977.

MEYER, K. Perspectives on Multinational Enterprises in Emerging Economies, Journal of International Business Studies, 35, 4, pp. 259-276, 2004.

MENEZES, N. B. A Política Governamental Brasileira de Incentivo à Internacionalização de Empresas (1997-2005). Seminário Brasileiro de estudos estratégicos internacionais SEBREEI. Integração Regional e Cooperação Sul-Sul no Século XXI. Porto Alegre, 2012.

NASCIMENTO, R. P.; BARRETO, F.; AVELINO, E.; GOMES, L. Vantagens da Estruturação em Redes para a Gestão de Empresas: Estudo de Caso no Setor de Supermercados. In: IV Simpósio de Excelência em Gestão e Tecnologia, Resende, 2007.

OLIVA, F. L.; ALMEIDA, M. I. R.; GRISI, C. C. H.; SANTOS, S. A.; FERREIRA, A. A. A Influência do Macroambiente Nacional na Definição e Implementação das Estratégias de Subsidiárias no Brasil. In: Encontro Luso-brasileiro de estratégia. Balneário Camboriú/SC, 2006.

PORTER, M. E. Competitive Strategy: Techniques for Analyzing Industries and Competitors. New York, New York: The Free Press, 1980.

Estratégia competitiva: técnicas para análise e da concorrência. 17 ed. Rio de Janeiro: Elsevier, 1999.

QI, L. The Relationship between Growth, Total Investment, and Inward FDI: Evidence from Time Series Data. International Review of Applied Economics, 21, 1, pp. 119-133, 2007.

ROMO, F. P.;SCHWARTZ, M., The Structural Embeddedness of Business Decisions: The Migration of Manufacturing Plants in New York State 1960 to 1985, American Sociological Review, 60, 6, pp. 874-907. 1995.

SANDBERG, S. Internationalization processes of small and medium size enterprises: Entering and taking off from emerging markets. Doctoral dissertation. School of Business and Economics, Linnaeus University, 2012.

SATO, G. S.; ANGELO, J. A. Exportações de vinhos e derivados e o processo de internacionalização das vinícolas brasileiras. Informações Econômicas. Instituto de Economia Agrícola, v. 37, p. 15-25, 2007.

SEGRE, L. M.; WERNER, A. Estratégias, Competências e Crescimento: uma visão sobre o segmento de supermercados. Adm. MADE (Universidade Estácio de Sá), Rio de Janeiro, v. 3, n.1, p. 1-15, 2003.

SIMON, H. A. A behavioral model of rational choice. The Quarterly Journal of Economics, v. 69, n. 1, p. 99-118, 1955.

STAL, E.; CAMPANARIO, M. A. Empresas multinacionais de países emergentes: o crescimento das multilatinas. Economia Global e Gestão, v. XIV, p. 55-73, 2010.

SHIFTER, M.; JAWAHAR, V., State Building in Colombia: Getting Priorities Straight. Journal of International Affairs, 58, 1, 2004, pp. 143-155.

TANURE, B.; CYRINO, A. B.; PENIDO, E. Estratégias de internacionalização: evidências e reflexões sobre as empresas brasileiras. In: FLEURY, Afonso; FLEURY, Maria Tereza L. (Org.). Internacionalização e os países emergentes. São Paulo: Atlas, p. 198- 215, 2007. 
DIEGO ECHEVENGUA BORGES, MARÍNDIA BRACHAK DOS SANTOS, VANESSA ALMEIDA DA SILVA, MARIA CAROLINA SERPA FAGUNDES DE OLIVEIRA, FLAVIA LUCIANE SCHERER, MAÍRA NUNES PIVETA

WENNBERG, K.; HOLMQUIST, C. Problemistic search and international entrepreneurship. European Management Journal, n. 26, p. 441- 454, 2008.

YIN, R. K. Estudo de Caso: planejamento e métodos. 2. ed. Porto Alegre: Bookman. 212p., 2001.

ZUCKER, L. G. The Role of Institutionalization in Cultural Persistence, American Sociological Review, 42, 5, p. 726743, 1977. 